\title{
Corrosion of 316H Stainless Steel in Flowing FLiNaK Salt
}

\author{
Stephen S. Raiman ${ }^{\mathrm{a}}$, J. Matthew Kurley ${ }^{\mathrm{b}}$, Dino Sulejmanovic ${ }^{\mathrm{c}}$, Adam Willoughby ${ }^{\mathrm{c}}$, Scott
} Nelson $^{b}$, Keyou Mao ${ }^{c}$, Chad Parish ${ }^{c}$, M. Scott Greenwood ${ }^{b}$, Bruce A. Pint ${ }^{c}$
a. Department of Nuclear Engineering, Texas A\&M University
b. Nuclear Energy and Fuel Cycle Division, Oak Ridge National Laboratory
c. Materials Science and Technology Division, Oak Ridge National Laboratory

\begin{abstract}
Type $316 \mathrm{H}$ stainless steel samples were exposed to flowing FLiNaK salt for $1000 \mathrm{~h}$ in a monometallic thermal convection loop (TCL) with a maximum temperature of $650^{\circ} \mathrm{C}$ and a minimum of $540^{\circ} \mathrm{C}$. Samples in the hottest part of the TCL lost mass, with a maximum mass loss of $1.4 \mathrm{mg} / \mathrm{cm}^{2}$, while samples in the coldest parts of the TCL gained mass, with a maximum mass gain of $1.0 \mathrm{mg} / \mathrm{cm}^{2}$. Analysis of the samples that gained mass showed an Fe-rich layer on the sample surfaces, suggesting that $\mathrm{Fe}$, not $\mathrm{Cr}$, accounted for the majority of the mass transfer in the TCL. However, Cr loss was apparent to a depth of $\sim 5 \mu \mathrm{m}$ in the HL. Post-exposure analysis of the salt showed major increases in the $\mathrm{Cr}$, Fe, and Mn contents. The TCL was modeled using the TRANSFORM code. Modeled values matched the experimental temperature measurements showing that TRANSFORM is capable of accurately simulating the TCL conditions.
\end{abstract}

\section{Introduction}

Molten salt reactors (MSRs) are a Generation IV technology that has gained increasing attention in recent years $[1,2]$. While the use of molten salts as coolant and/or fuel media offers many advantages, salt compatibility with structural materials must be ensured before deployment of an MSR. Materials testing for molten salt compatibility dates back to the Aircraft Nuclear Propulsion (ANP) program at Oak Ridge National Laboratory (ORNL) in the 1950s [3], and continued throughout the Molten Salt Reactor Experiment (MSRE) and Molten Salt Breeder Reactor (MSBR) programs in the 1960s and 1970s[4-9]. The primary concern is not necessarily the corrosion of materials in contact with the salt but that mass transfer due to interaction between the salt and structural alloys will deposit material in colder sections of the circuit and inhibit or even block flow with graphic examples for fluoride salts documented []. W. Koger, "Corrosion Product Deposition in Molten Fluoride Salt Systems," Corrosion 30(4) (1974) 125-130.].

Because of the concern about mass transfer, ORNL scientists made extensive use of natural and forced convection flowing experiments to test alloy compatibility with molten salts[3,9-13]. While a static test is easier and less expensive, the eventual saturation of the static salts with

This manuscript has been authored by UT-Battelle, LLC under Contract No. DE-AC05-00OR22725 with the U.S. Department of Energy. The United States Government retains and the publisher, by accepting the article for publication, acknowledges that the United States Government retains a non-exclusive, paid-up, irrevocable, worldwide license to publish or reproduce the published form of this manuscript, or allow others to do so, for United States Government purposes. The Department of Energy will provide public access to these results of federally sponsored research in accordance with the DOE Public Access Plan (http://energy.gov/downloads/doe-publicaccess-plan). 
corrosion product limits the usefulness of static testing for studying compatibility and predicting corrosion rates. By circulating salt through a loop that imposes a change in temperature as salt traverses the circuit, corrosion associated with mass transfer can be driven indefinitely without saturating the salt with corrosion products. The driving force for corrosion over long time scales in a flowing system is the collection of temperature-dependent equilibria that result in the depletion of alloy components in the hottest parts of the loop, and the deposition of corrosion products in the cold parts of the loop[3,6,14,15]. Loops with a temperature differential mimic the conditions in an MSR in which salt would be hottest in the reactor core, and colder in the heat exchanger.

Thermal convection loops (TCLs) have been used since the ANP program to test material-salt combinations and evaluate salt-alloy combination before moving to forced convection loops $[3,13]$. Central to the TCL design are a pair of vertical tube lengths, one heated and one not heated. The difference in salt density between the two vertical sections creates a natural convective flow that circulates the salt in the TCL without the expense and complexity of a pump or valves. Since the MSRE era, TCLs have been used to study compatibility with salt and liquid metal for fision and fusion energy[16-20]. With the recent surge in interest in MSRs, TCLs have been operated at the Kurchatov Institute [21] and The University of Wisconsin [22] and ORNL $[23,24]$

A great deal of early work on material compatibility with fluoride salts was focused on Ni-based alloys. Alloy N, developed at ORNL specifically for use as a fluoride salt-facing structural material [25,26], was used extensively in the MSRE [27]. Recent attention has turned to evaluating the compatibility of molten salts with stainless steels [28-31]. Stainless steels were the subject of some study during the MSRE era as well[5,8,32] with higher mass losses compared to alloy $\mathrm{N}$ [9]. Type $316 \mathrm{H}$ is the high-carbon version of type 316 stainless steel (SS), and is ASME Boiler and Pressure Vessel Code qualified for higher-temperature service. It is attractive because it is widely available in common forms, and is less expensive than Ni-based alloy $\mathrm{N}$.

To move beyond the static testing available in the recent literature, the purpose of this work was to evaluate corrosion and mass transfer of type $316 \mathrm{H} \mathrm{SS}$ in flowing fluoride salt to better understand the mechanisms involved. Prior studies only reported mass change data with no characterization of the reaction products [8,9]. For this first experiment, coupons were exposed to flowing FLiNaK salt with a maximum temperature of $650^{\circ} \mathrm{C}$ in a TCL. The samples were characterized to understand the extent and nature of mass transfer and compared to similar specimens exposed in static experiments. A TRANSFORM model was created to understand the heat flow in the TCL.

\section{$\underline{\text { TCL Construction }}$}

\section{Experiment}

Exposures were conducted in a redesigned 316H stainless steel TCL. A photograph, 2D drawing and a 3-D rendering of the TCL are shown in Figure 1. The loop section was constructed from $3 / 4$ " schedule-40 type $316 \mathrm{H}$ stainless steel pipe, with an outer diameter of $26.7 \mathrm{~mm}$, an inner diameter of $20.8 \mathrm{~mm}$, and a wall thickness of $2.79 \mathrm{~mm}$. All dimensions are nominal, and based on 
ASTM A53[33]. An overflow tank was positioned at the top of the hot leg (HL), and a SS fill tank was connected above that. Three $900 \mathrm{~W}$ heaters were positioned on the loop, two on the HL and one on the bottom leg. The whole loop was wrapped in heating tape to allow for greater control over temperature. Thermocouples were positioned in thermowells around the loop, as indicated in Figure 1b.
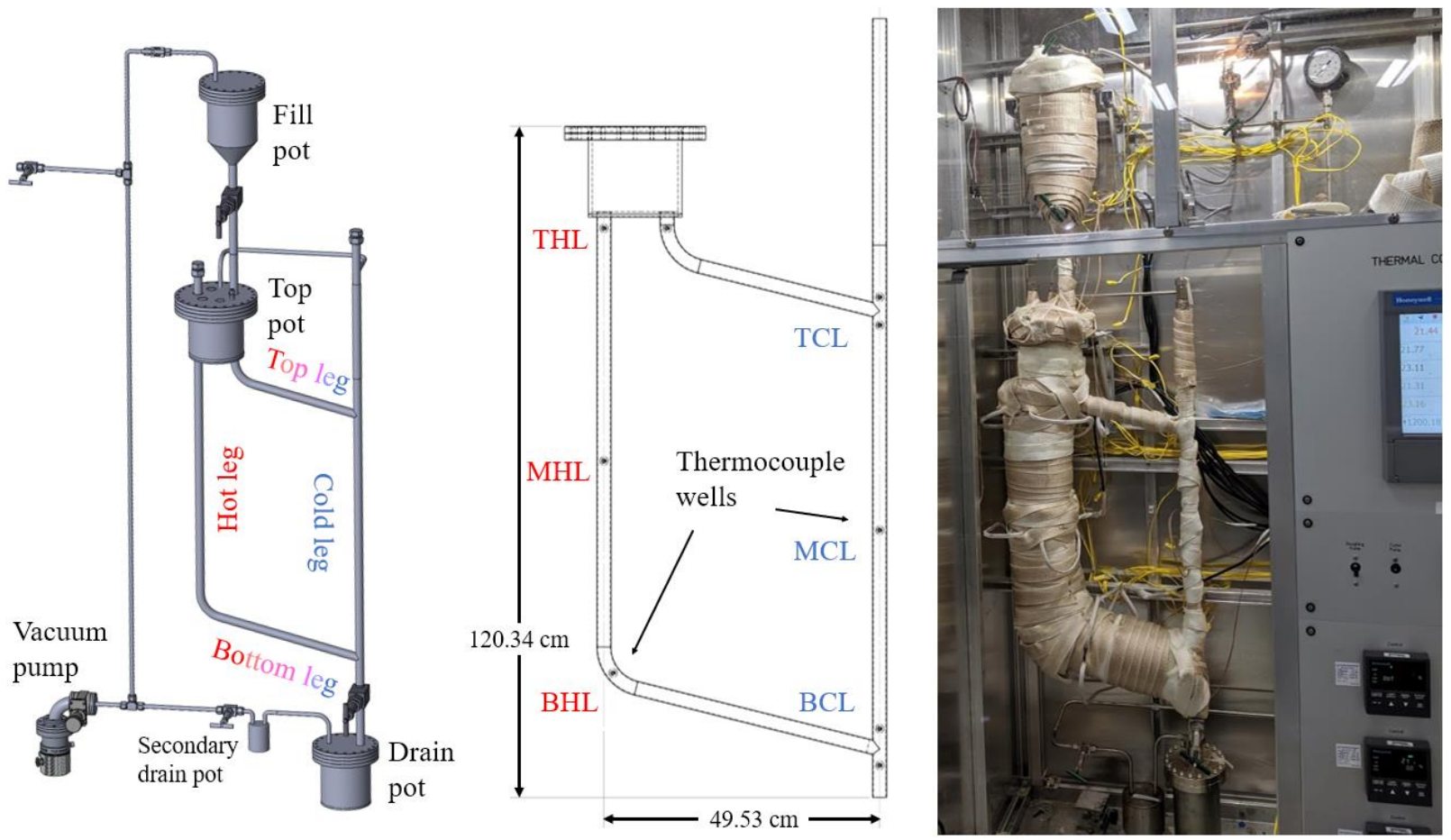

Figure 1. The 316H thermal convection loop used for this study. (a)A 3D rendering, (b) 2D drawing, and (c) a photograph of the TCL with heaters and insulation. In (b), thermowells are shown at the top (T), middle (M) and bottom (B) of the hot leg (HL) and cold leg (CL).

\section{$\underline{\text { Salt preparation }}$}

The FLiNaK salt used for this work was prepared by Electrochemical Systems, a now defunct company that specialized in salt purification for research projects. It was recovered from oldstock, stored in airtight Ni alloy vessels. Salts were handled exclusively in Ar-filled gloveboxes $\left(\mathrm{O}_{2}\right.$ and $\left.\mathrm{H}_{2} \mathrm{O}<0.1 \mathrm{ppm}\right)$, so moisture did not come in contact with the salts at any stage. Due to the age of the salt, details of its provenance are unknown, although hydrofluorination is believed to have been the primary method of impurity removal[34]. The as-received salt was analyzed in triplicate with inductively coupled plasma mass spectroscopy (ICP-MS) by the University of Wisconsin Hygiene Lab, and the results are shown in Table 1. Due to the lack of a reliable method for measuring moisture content, only metallic impurities are reported. Previous reports of similar FLiNaK salts from the same source suggested it was relatively pure with low corrosivity[35]. The $366 \mathrm{ppm}$ of $\mathrm{Zr}$ in the salt is notable, and may have accounted for the low observed corrosion rate[36]. Cheng et al. observed $\mathrm{Zr}$ deposition on stainless steel samples 
exposed to FLiNaK salt with $\mathrm{Zr}$ addition, [37] although the $\mathrm{Zr}$ concentration in the salt used for that work $(1.9 \%)$ was much higher than in the salt used for the present work

Table 1. Salt contents before exposure, as measured by ICP-MS. All values in $\mu \mathrm{g} / \mathrm{g}$.

\begin{tabular}{|c|c|c|c|c|c|c|c|}
\hline $\mathbf{K}$ & $\mathbf{N a}$ & $\mathbf{L i}$ & $\mathbf{Z r}$ & $\mathbf{B a}$ & $\mathbf{C a}$ & $\mathbf{T i}$ & $\mathbf{M g}$ \\
\hline 385427.3 & 75409.95 & 74920 & 366.31 & 147.49 & 75.013 & 56.17 & 20.93 \\
\hline $\mathbf{R b}$ & $\mathbf{A l}$ & $\mathbf{F e}$ & $\mathbf{N i}$ & $\mathbf{C r}$ & $\mathbf{S}$ & $\mathbf{S r}$ & $\mathbf{H f}$ \\
\hline 17.23 & 12.46 & 7.17 & 6.66 & 4.57 & 4.56 & 2.06 & 0.99 \\
\hline $\mathbf{M n}$ & $\mathbf{S e}$ & $\mathbf{B}$ & $\mathbf{S c}$ & $\mathbf{A g}$ & $\mathbf{B e}$ & $\mathbf{P}$ & $\mathbf{M o}$ \\
\hline 0.88 & 0.70 & 0.53 & 0.39 & 0.37 & 0.26 & 0.22 & 0.16 \\
\hline
\end{tabular}

Sample preparation

Samples were cut from $316 \mathrm{H}$ plate. The composition of the heat is given in Table 2. Composition was measured using ICP-MS and optical emission spectroscopy, inert gas fusion, and combustion analysis. Two types of samples were prepared. 12 coupons measuring $25.4 \times 19 \times 2$ $\mathrm{mm}$ and $28 \mathrm{SS}-3$ tensile specimens. The specimens were arranged in chains held together by $316 \mathrm{SS}$ wire and are shown in Figure 2. Spacers were positioned at the top and middle of each chain to ensure that the chains remained centered within the vertical tubing of the TCL.

Table 2. Composition of the heat of type $316 \mathrm{H}$ SS used to make samples for this work, determined by ICP-MS and combustion analyses.

\begin{tabular}{|l|l|l|l|l|l|l|l|l|l|}
\hline $\mathrm{Fe}$ & $\mathrm{Ni}$ & $\mathrm{Cr}$ & $\mathrm{Mo}$ & $\mathrm{Mn}$ & $\mathrm{Si}$ & $\mathrm{C}$ & $\mathrm{S}$ & $\mathrm{O}$ & others \\
\hline 64.5 & 13.3 & 17.2 & 2.3 & 1.9 & 0.54 & 0.058 & 0.016 & 0.008 & $\mathrm{Cu} 0.08$ \\
\hline
\end{tabular}

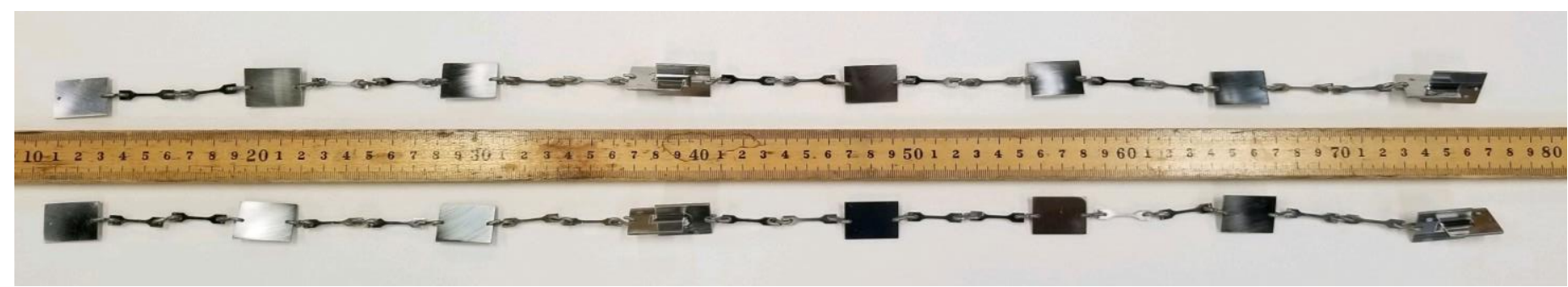

Figure 2. 316H sample chains that were hung in the vertical portions of the loop, one in the hot leg, and one in the cold leg.

\section{Capsule testing}

As a preliminary step, $316 \mathrm{H}$ samples measuring $12.7 \times 6.4 \mathrm{~mm}$ were statically exposed to the same FLiNaK salt in $316 \mathrm{H}$ or low carbon arc cast molybdenum capsules. Each cylindrical capsule measured $7.6 \mathrm{~cm}$ in length by $2.5 \mathrm{~cm}$ in diameter. Samples were tethered to one end of each capsule, and capsules were filled with $30 \mathrm{~g}$ of solid FLiNaK salt. The capsules were welded 
shut (gas tungsten arc) in the same Ar-filled glovebox without exposure to air. The capsules were then sealed (electron beam welded) within outer SS capsules to provide secondary containment. The capsule testing procedure has been described in detail elsewhere [38]. A total of 12 capsules were heated in a box furnace for $1000 \mathrm{~h}$ in $316 \mathrm{H}$ or molybdenum capsules at either 550 or $650^{\circ} \mathrm{C}$.

\section{$\underline{\text { TCL Testing Procedure }}$}

Sample chains were hung from the top of the vertical portions of the loop with type alloy 600 wire measuring $~ 16$ " long on the HL, and 24 " on the cold leg (CL). This wire represents the only dissimilar metal in the TCL, and its surface area was relatively small and unlikely to affect corrosion of the other specimens. The upper fill pot was loaded with $\sim 5 \mathrm{~kg}$ of FLiNaK salt in an inert glovebox, sealed, and positioned on top of the TCL. With the TCL sealed, it was pumped down to a vacuum of $\sim 7 \times 10^{-3} \mathrm{~Pa}$, heated to $\sim 200^{\circ} \mathrm{C}$, and allowed to out-gas for $\sim 2.5$ days.

To begin the experiment, the entire loop including the fill pot was heated above the melting point of FLiNaK $\left(454^{\circ} \mathrm{C}\right)$ using the furnaces and heating tape. The SS valve below the fill pot was opened, and the salt was allowed to drain into the body of the TCL, filling it to a depth approximately half way up the pot above the HL. The HL furnaces were used to achieve a maximum target temperature of $650^{\circ} \mathrm{C}$ at the top of the $\mathrm{HL}$, and $550^{\circ} \mathrm{C}$ at the bottom of the $\mathrm{CL}$, which was sufficient to drive convective flow around the loop.

The TCL was operated for $1000 \mathrm{~h}$ at steady state. At the conclusion of the $1000 \mathrm{~h}$, the SS valve at the bottom of the CL was heated and then opened, allowing the salt to immediately flow into the drain tank, where it cooled to room temperature, along with the TCL. The drain tank was removed from the TCL and stored in a glovebox so the salt could be analyzed. The solid salt was briefly exposed to air (<10 minutes) during this transfer, but surface area was minimal due to the single solid form of the salt. The TCL was filled with deionized (DI) water and drained 3 times to remove residual salt from the samples, followed by a rinse with acetone before the sample chains were removed.

\section{Characterization}

Individual samples were cleaned by sonicating in $\sim 50^{\circ} \mathrm{C}$ DI water for at least $1 \mathrm{~h}$ to remove any further traces of residual salt. Specimen mass change was measured with a Mettler Toledo model XP205 balance with an accuracy of $\pm 0.04 \mathrm{mg}$. Samples were cross-sectioned, mounted in epoxy, polished, and imaged optically with a Leica model MEF4A microscope. Samples were also characterized with scanning electron microscopy (SEM) and energy dispersive spectroscopy (EDS) mapping on a Hitachi S-4800 equipped with EDAX hardware. Salts were analyzed by ICP-MS on a Thermo-Finnigan Element 2 instrument. Samples were digested using microwave digestion in $7.0 \mathrm{~mL}$ of $16 \mathrm{M}$ nitric acid, $3.0 \mathrm{~mL}$ of $12 \mathrm{M}$ hydrochloric acid, $2.0 \mathrm{~mL}$ of $28 \mathrm{M}$ hydrofluoric acid and $3.0 \mathrm{~mL}$ of DI water. After digestion, samples were diluted using several different ratios to account for a wide range of concentrations of analytes.

\section{Results}


After cleaning, the samples exposed to static FLiNaK salt in capsules were weighed and the individual and average mass loss results are shown in Figure 3. The samples exposed in $316 \mathrm{H}$ capsules had less mass loss than samples exposed in Mo capsules. In both cases, the samples exposed at $650^{\circ} \mathrm{C}$ lost more mass than the samples exposed at $550^{\circ} \mathrm{C}$.

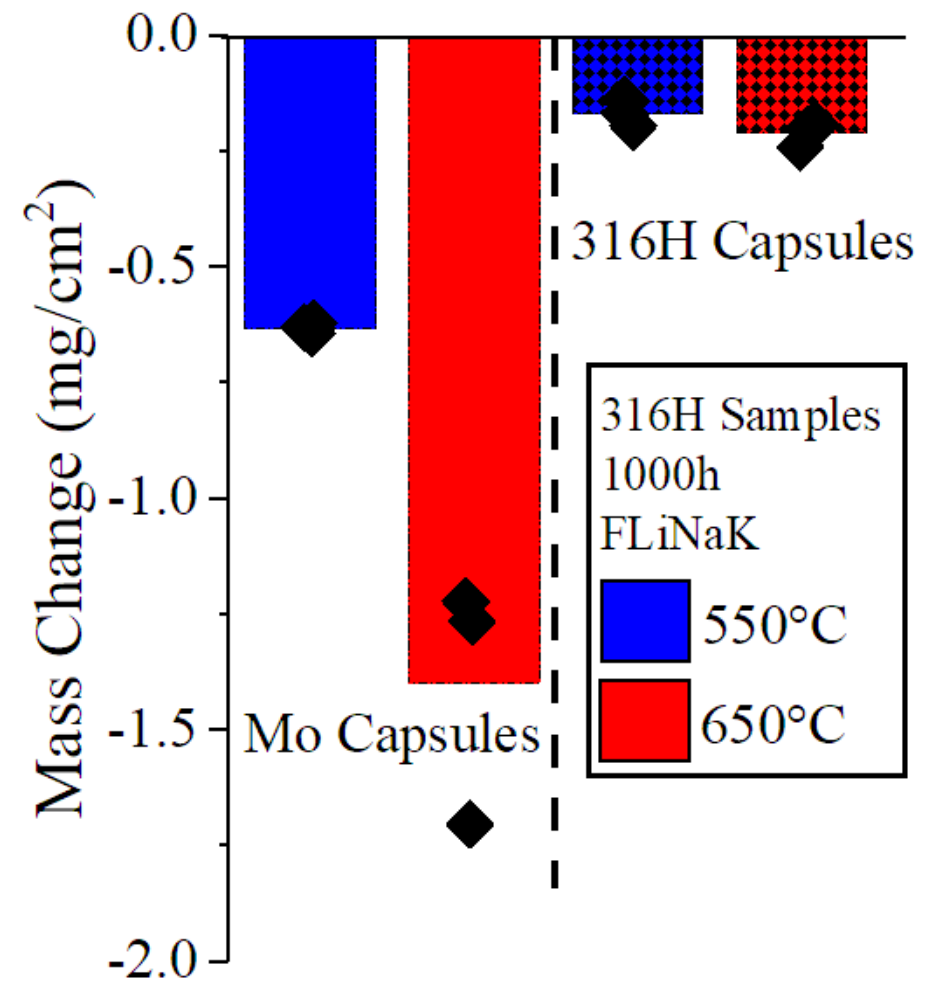

Figure 3. Mass change of $316 \mathrm{H}$ samples exposed to FLiNaK salt in $316 \mathrm{H}$ or Mo capsules for $1000 \mathrm{~h}$ at 550 or $650^{\circ} \mathrm{C}$. The diamonds show individual values and the bars are the average mass losses.

The coupon samples exposed in the TCL were also measured for mass change, and the results are shown in Figure 4 where the specimen mass change is plotted versus the estimated exposure temperature. The temperature of each sample was not measured directly, but modeled in TRANSFORM (see discussion section). To determine the temperature of each sample, a linear rate of temperature change was assumed between the thermocouples in the HL and CL, and a temperature for each sample was assigned based on its position within the leg. The hottest samples were at the top of the HL, and the coldest samples were at the bottom of the CL. All the samples in the HL lost mass, with a maximum mass loss of $1.8 \mathrm{mg} / \mathrm{cm}^{2}$. Samples in the CL gained or lost mass, with a maximum gain of $1.1 \mathrm{mg} / \mathrm{cm}^{2}$ and a maximum loss of $0.6 \mathrm{mg} / \mathrm{cm}^{2}$. The mass change as a function of temperature appears roughly linear in Figure 4. 


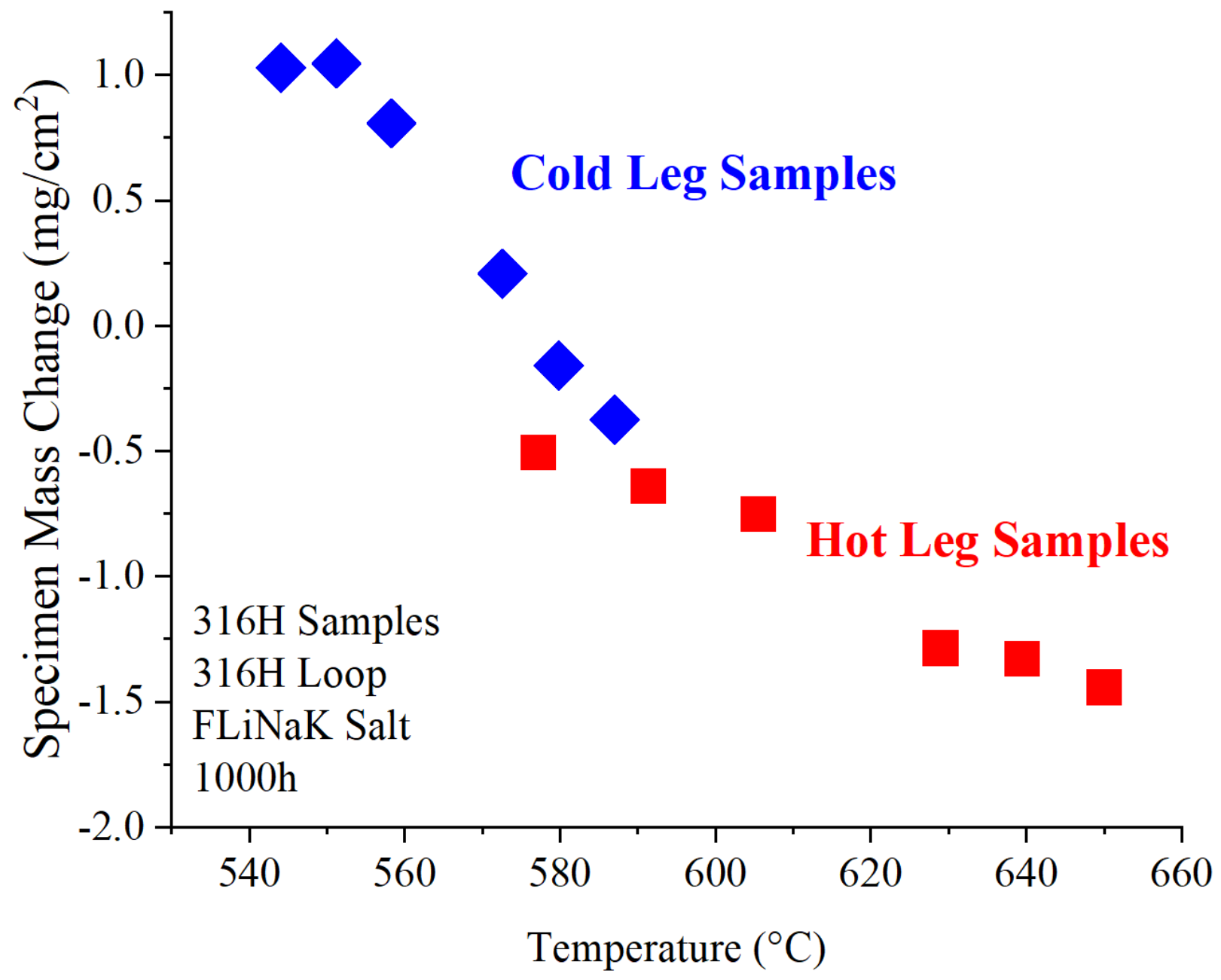

Figure 4. Mass change of 316H samples exposed to flowing FLiNaK salt for 1000h.

Light micrographs of the coupon polished cross-sections are shown in Figure 5. Subsurface attack is visible on HL samples H1-H6. A deposited layer is visible on samples C7-C12 and on H5-H6. Samples H5, H6, C7, and C8 all lost mass (Figure 4) suggesting that some of the original metal under the deposited layer must have been lost. 


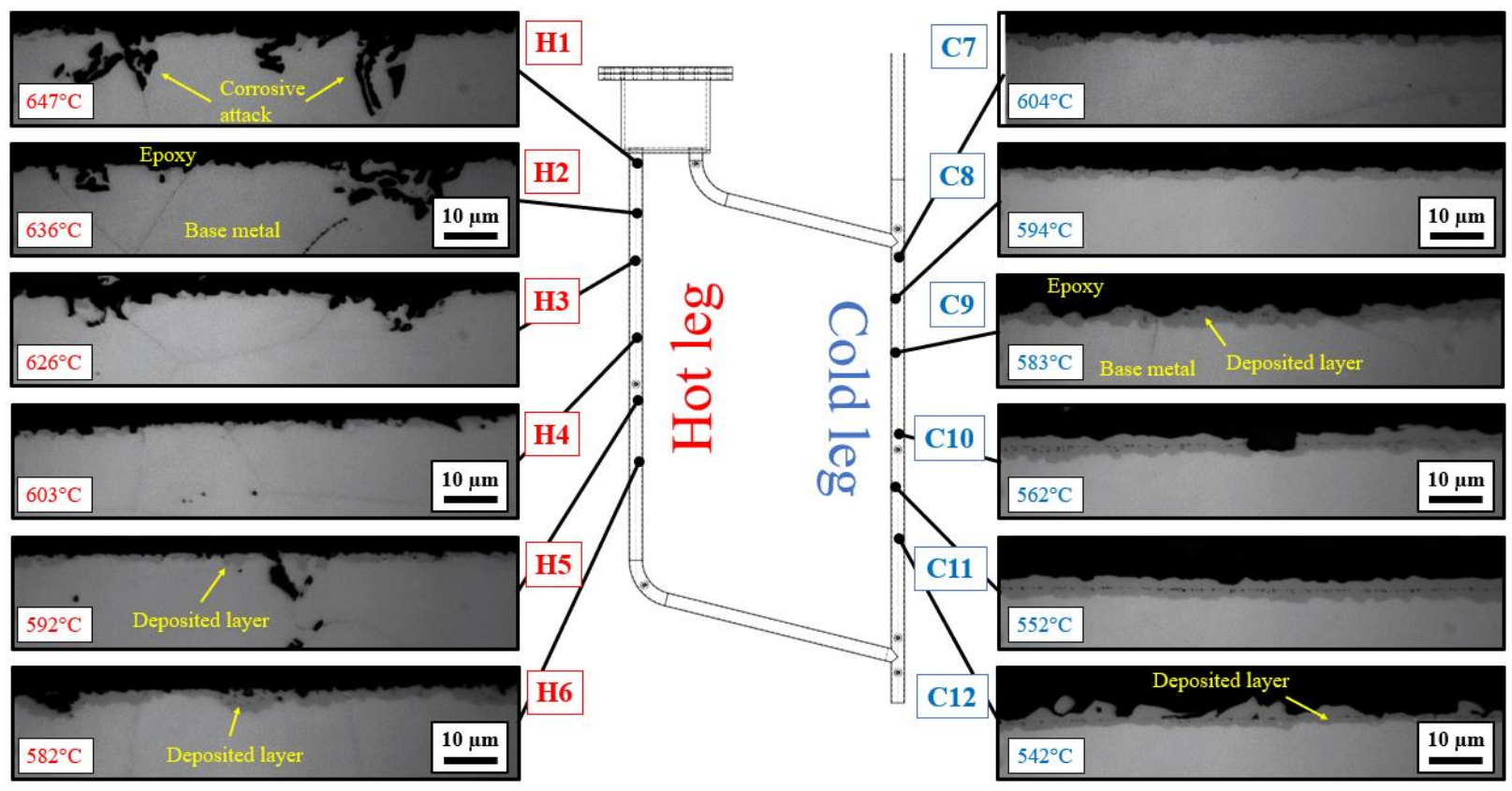

Figure 5. Light micrographs of 316H samples exposed for 1000h to flowing FLiNaK salt. Samples temperatures are from the TRANSFORM simulation, and sample locations are approximate

For each sample, depth of attack (for samples in the HL) or thickness of the deposited layer (for samples in the CL) was measured using image analysis and the results are shown in Figure 6. The hottest sample had an average depth of attack of $5 \mu \mathrm{m}$, while the coldest sample had a deposition layer with an average thickness of $3 \mu \mathrm{m}$. 


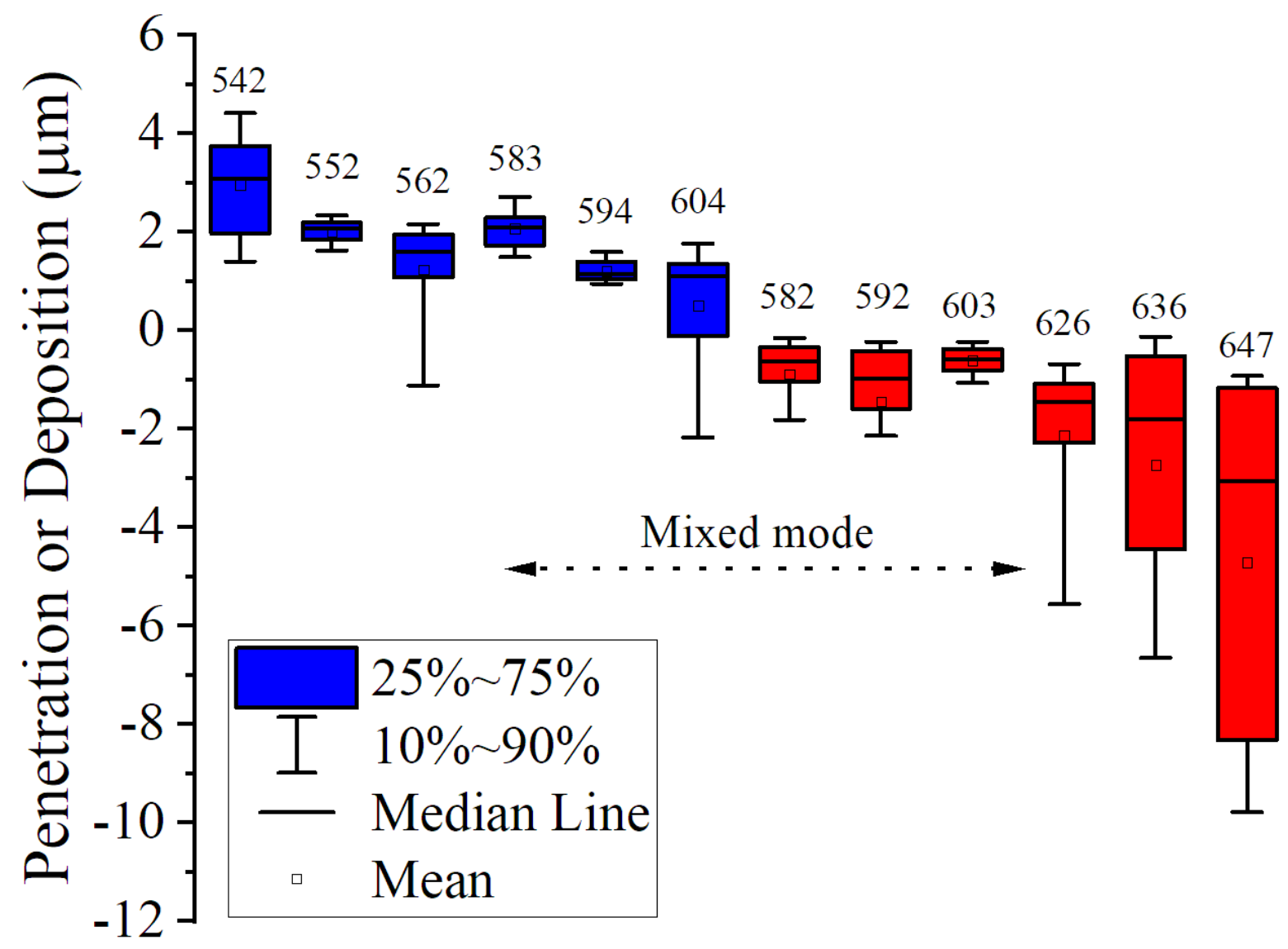

Figure 6. Depth of attack or thickness of the deposition layer for $316 \mathrm{H}$ samples exposed to flowing FLiNaK salt for $1000 \mathrm{~h}$. Calculated temperature of each sample in ${ }^{\circ} \mathrm{C}$ is displayed above each box.

EDS line scans were taken on each sample, and the results are shown in Figure 7. All of the CL samples have a deposit on the surface that is rich in $\mathrm{Fe}$ and low in $\mathrm{Cr}$, and that is reflected in the line scans. Samples H5 and H6, the samples closest to the bottom of the HL, also have an Fe-rich deposit layer in addition to subsurface attack. The Ni content of the deposited layer in samples H5, H6, C7, and C8 is either the same as the bulk metal, or slightly higher. The line scans of samples C9-C12 show a deposited layer depleted in Ni. Line scans of the HL samples without a deposited layer, samples H1-H4, show Cr depletion near the surface. Iron is also depleted near the surface except on sample 3. Samples H1-H4 are also enriched in Ni near the surface.

SEM-EDS maps of samples $\mathrm{H} 1$ and $\mathrm{C} 11$ are shown in Figure 8. The attacked region on sample $\mathrm{H} 1$ is enriched in $\mathrm{Ni}$, and depleted in $\mathrm{Fe}$ and $\mathrm{Cr}$. Mo precipitates are visible in the attacked region. Sample $\mathrm{C} 11$ has a deposited layer rich in $\mathrm{Fe}$, with little $\mathrm{Ni}, \mathrm{Cr}$, and $\mathrm{Mn}$. Mo precipitates are also visible in the deposited layer. 


\section{Hot Leg}

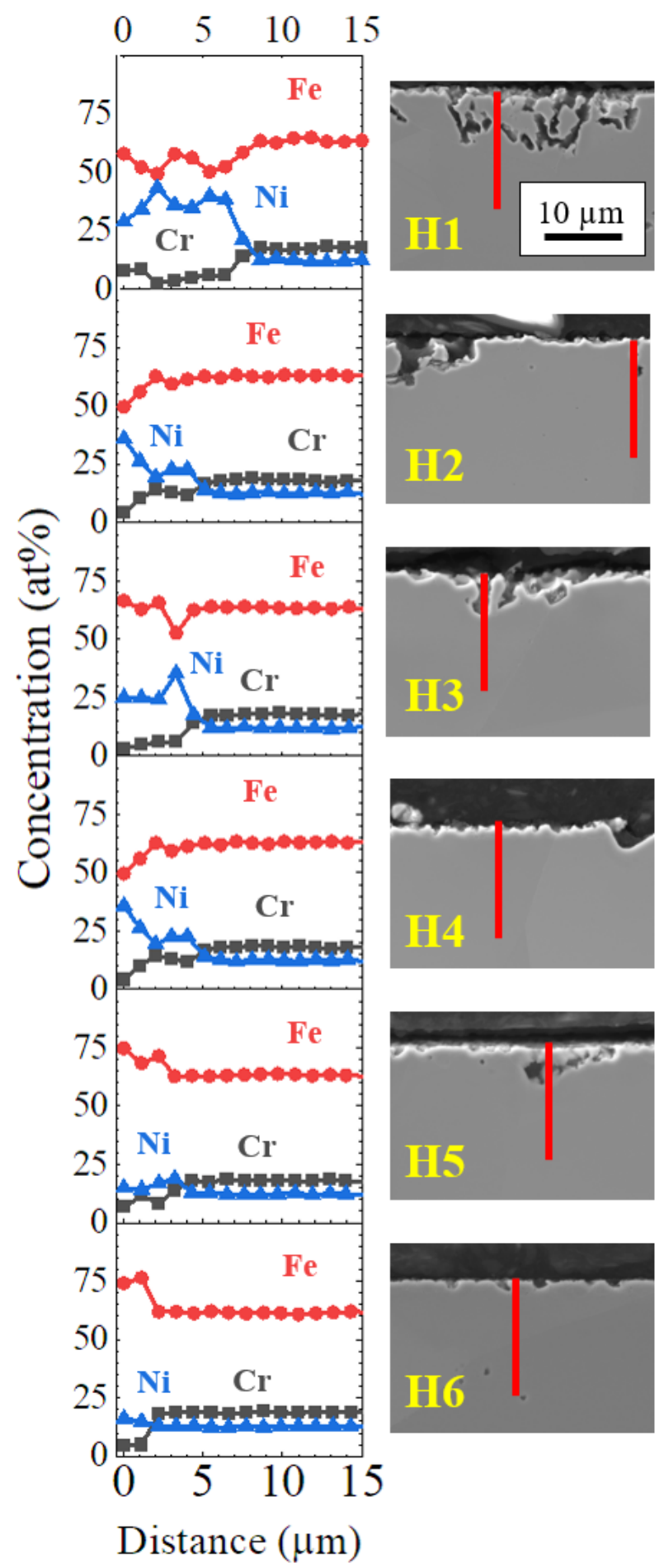

Cold Leg

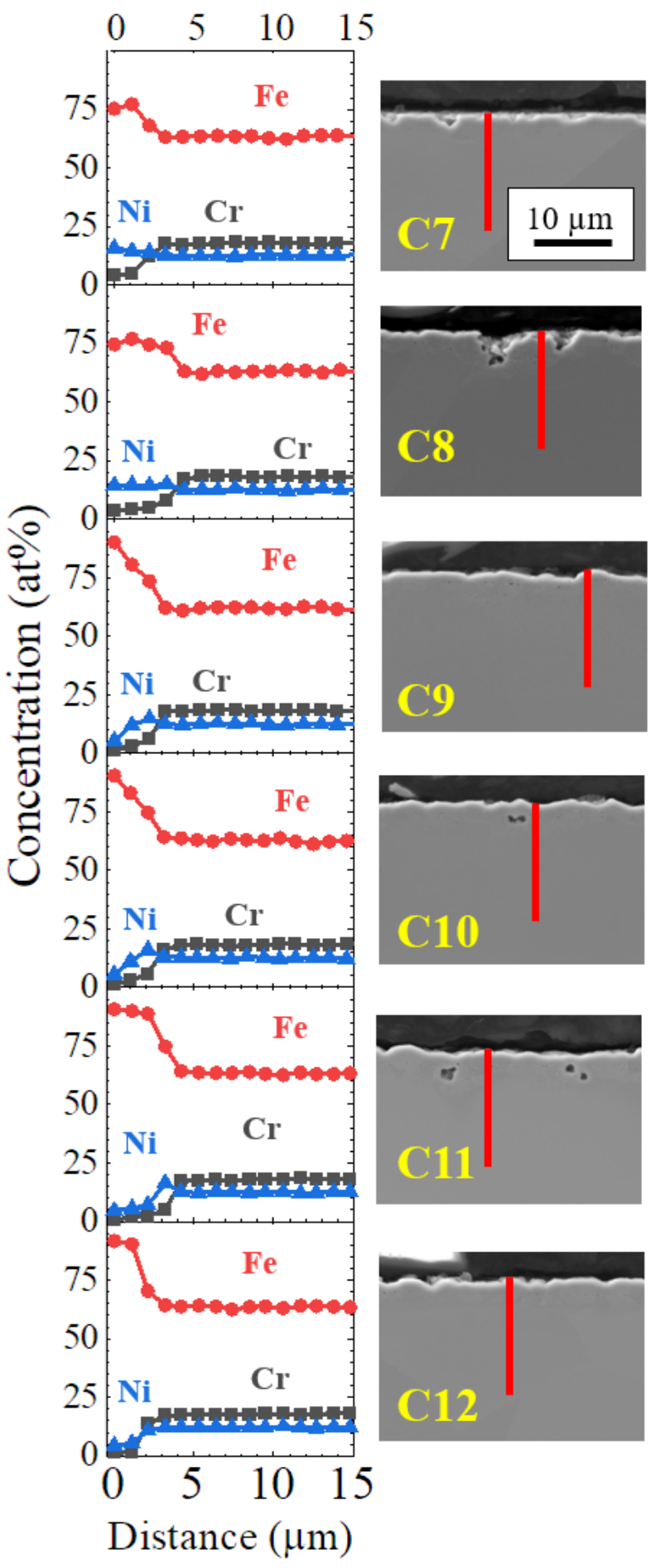

Figure 7. EDS scans of samples exposed to FLiNaK salt for $1000 \mathrm{~h}$ at various locations in the TCL 


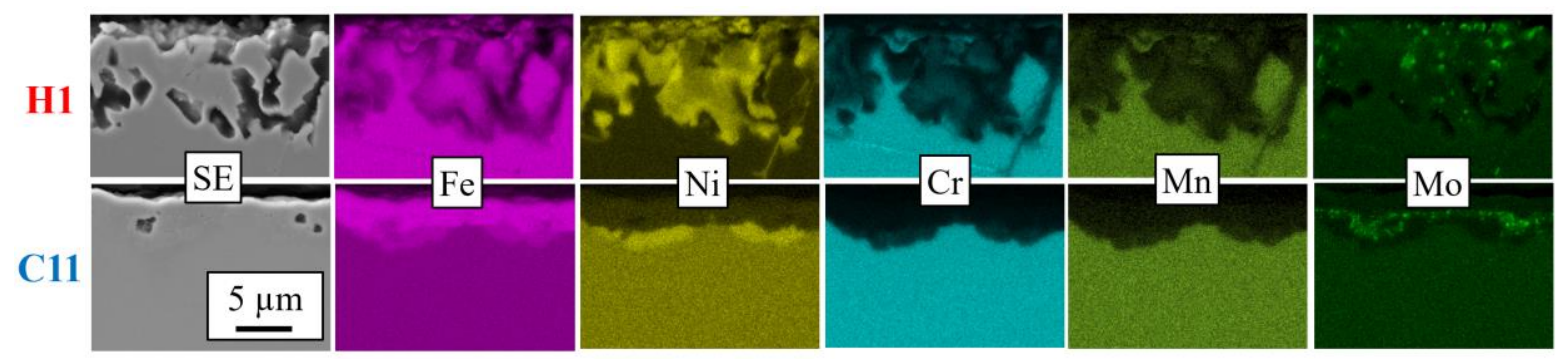

Figure 8. EDS map of $316 \mathrm{H}$ samples $\mathrm{H} 1$ and $\mathrm{C} 11$ exposed to flowing FLiNaK salt for $1000 \mathrm{~h}$ at 647 and $552^{\circ} \mathrm{C}$ respectively

To further investigate the composition of the deposition layer, transmission electron microscopy (TEM) micrographs of samples H6 and C7 are shown in Figure 9. On H6, the metal is mostly Fe and $\mathrm{Ni}$ with $\mathrm{Cr}$ depleted from the matrix, but $\mathrm{Cr}$ and Mo-rich precipitates are visible throughout the matrix. Mo-rich precipitates are also visible near the surface and along what appears to be a grain boundary. On sample $\mathrm{C} 7$, the deposition layer is visible above the metal surface. The layer was Fe-rich oxide, although this may be due to air oxidation of the focused ion beam (FIB) lamella, as the Cr-depleted deposition layer would be susceptible to air oxidation. $\mathrm{Cr}$ and Mo precipitates are also visible in the metal matrix, and Mo-rich precipitates are visible in the deposition layer.
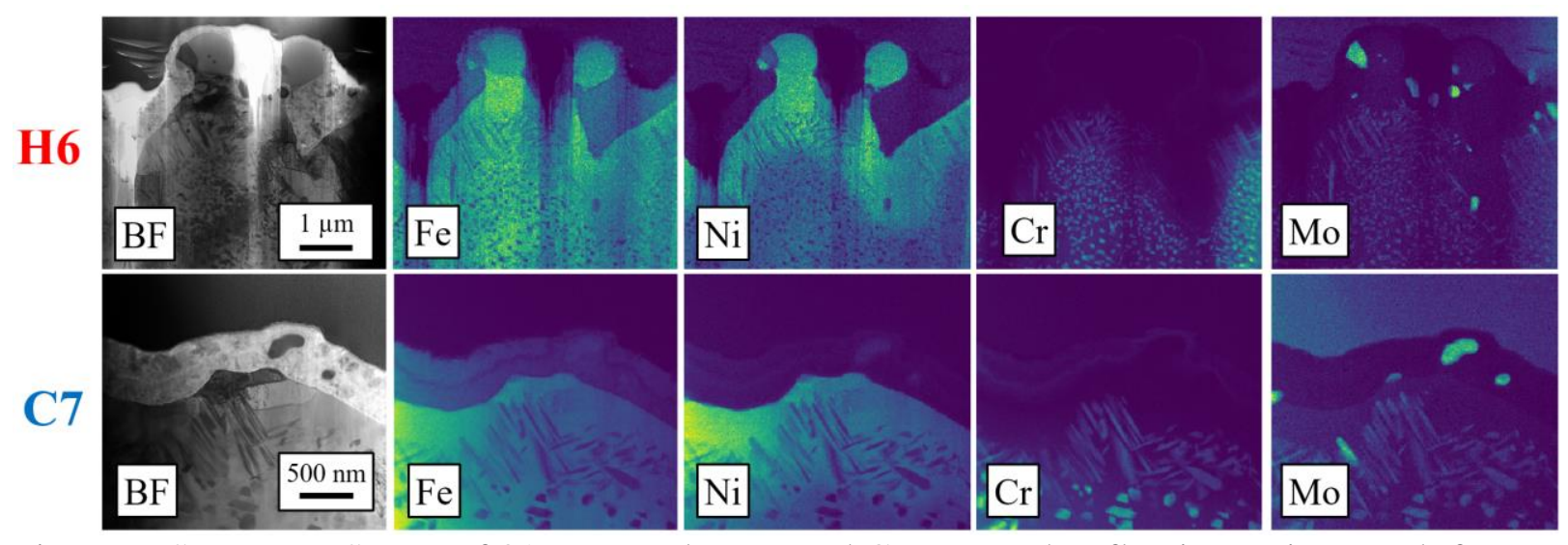

Figure 9. STEM-EDS map of 316H samples H6 and C7 exposed to flowing FLiNaK salt for $1000 \mathrm{~h}$ at 582 and $604^{\circ} \mathrm{C}$ respectively

The concentration of metallic species in the salt was measured with ICP-MS before and after exposure, and the results are shown in Figure 10. The content of Fe, $\mathrm{Cr}$, and $\mathrm{Mn}$ in the salt increased dramatically during exposure, while the Ni content decreased slightly. 


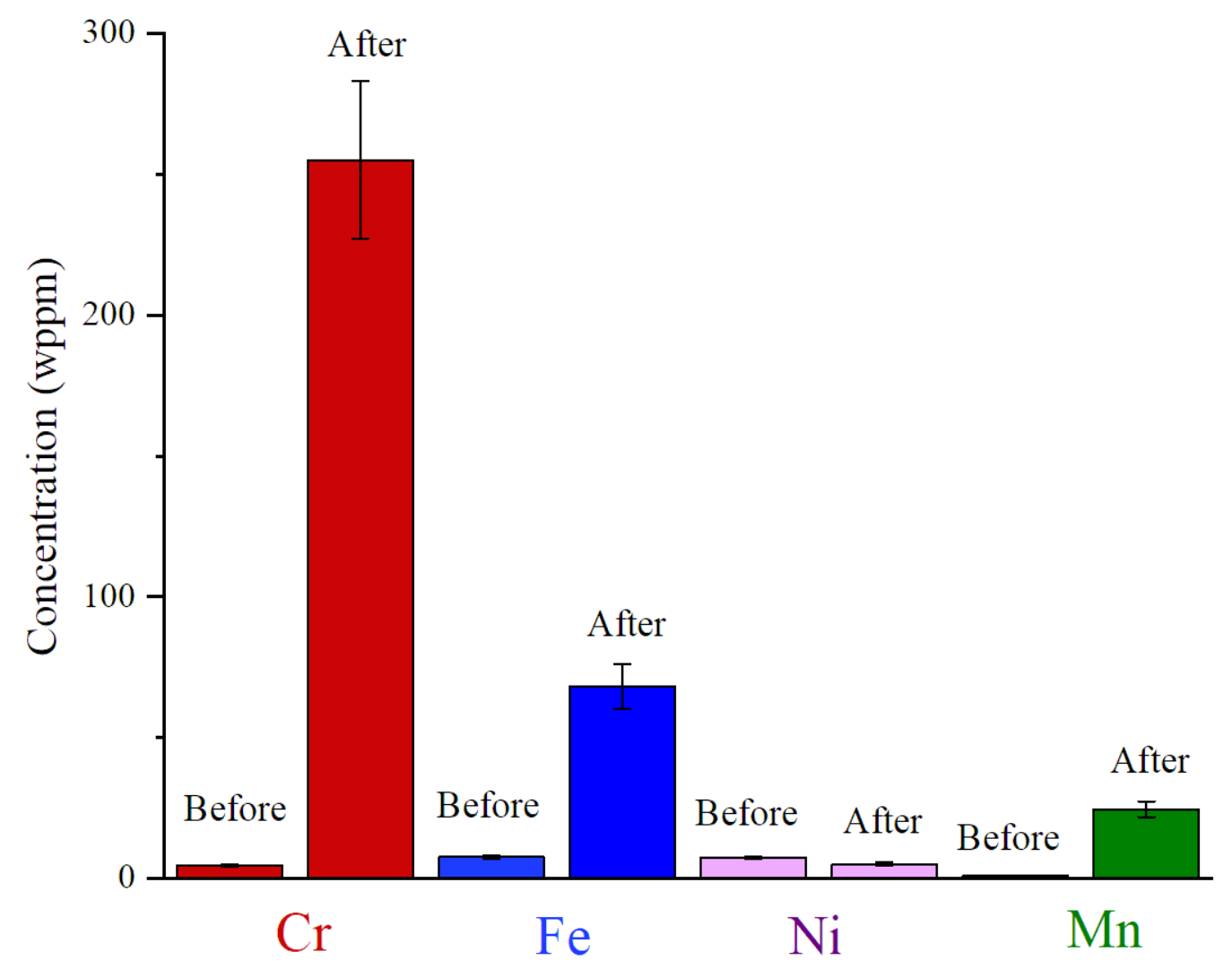

Figure 10. Concentration of metallic species in FLiNaK salt before and after flowing for 1000h in the $316 \mathrm{H}$ TCL.

\section{TCL Temperature Model}

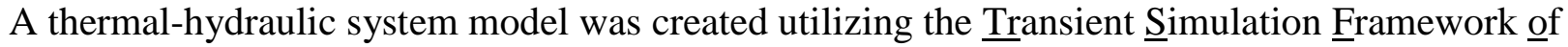

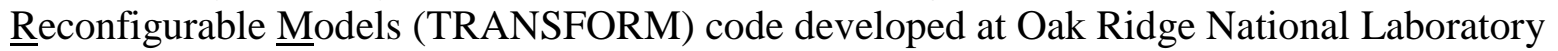
[39]. TRANSFORM has been used to model natural and forced circulation molten salt loops [40]. However, the previous natural circulation models were larger, and thus did not have the low Reynolds number flow regimes in the present work. TRANSFORM was chosen as the modeling tool for this work because of its drag-and-drop setup, complex linear and non-linear solution routines, and emphasis on fundamental constitutive equations that allow for fast and accurate solutions with potential for easy reconfiguration. The generic default heat transfer and fluid flow models of TRANSFORM were used, i.e. no additional models specific to the problem were needed. The dimensions utilized in the model were taken from the drawing shown in Figure 1.

In the simulation, shown in Figure 11, each pipe was modeled as a single connected loop in TRANSFORM with multiple nodes within each pipe. The HL contained one node for each coupon, spacer and tensile bar, with a final empty node for the remaining empty section of pipe. A heat flux boundary condition of 1800 Watts (two $900 \mathrm{~W}$ heaters) was imposed on the pipe heat transfer surface. The sloped bottom leg, which was heated by another $900 \mathrm{~W}$ heater, was modeled with internal heat generation only, a simpler method. Generally, pipes that do not contain test samples such as the bottom leg can be modeled with less detail. 
The CL pipes were modeled as pipes with a single heat transfer surface, as with the HL. The heat transfer surface is then given a convection resistance condition that is connected to an ambient temperature boundary condition of $21^{\circ} \mathrm{C}$ with the surface area determined by the geometry of the pipe. Typically, a boundary condition such as this will have a heat transfer coefficient $\alpha$ determined by a Nusselt number correlation that relates the Raleigh number to the Nusselt number.

$$
\begin{aligned}
& \alpha=\frac{N u * k}{L} \\
& N u=C_{1} R a^{n} \\
& R a=G r P r \\
& G r=\frac{g \beta \Delta T L^{3}}{v^{2}} \\
& \operatorname{Pr}=\frac{C_{p} \mu}{k}
\end{aligned}
$$

Where:

$$
\begin{aligned}
& \mathrm{L}=\text { Characteristic Dimension } \\
& \mathrm{k}=\text { Thermal conductivity } \\
& \mathrm{g}=\text { Gravitational constant } \\
& \beta=\text { Coefficient of thermal Expansion }\left(1 / \mathrm{T}_{\text {fluid }}\right) \\
& \Delta \mathrm{T}=\mathrm{T}_{\text {surface }}-\mathrm{T}_{\text {ambiant }} \\
& \nu=\text { Kinematic viscosity } \\
& \mathrm{Cp}=\text { Specific heat capacity } \\
& \mu=\text { Dynamic viscosity }
\end{aligned}
$$

However, due to the presence of heat tape added to the piping components this correlation will not hold true and must be adjusted. To correct for the presence of a non-uniform heat tape, thermocouples were added to the model to match the positions at the inlet and outlet of each leg of the TCL and monitored by a PID controller that was instructed to adjust the constants of the heat transfer coefficient to maintain the $\Delta \mathrm{T}$ between the upper pipe and CL to match the measured $\Delta \mathrm{T}$. Resistances were added to the model to represent the various bends and pipe losses throughout the natural circulation TCL and calibrated to give the proper $\Delta \mathrm{T}$ across the HL. 


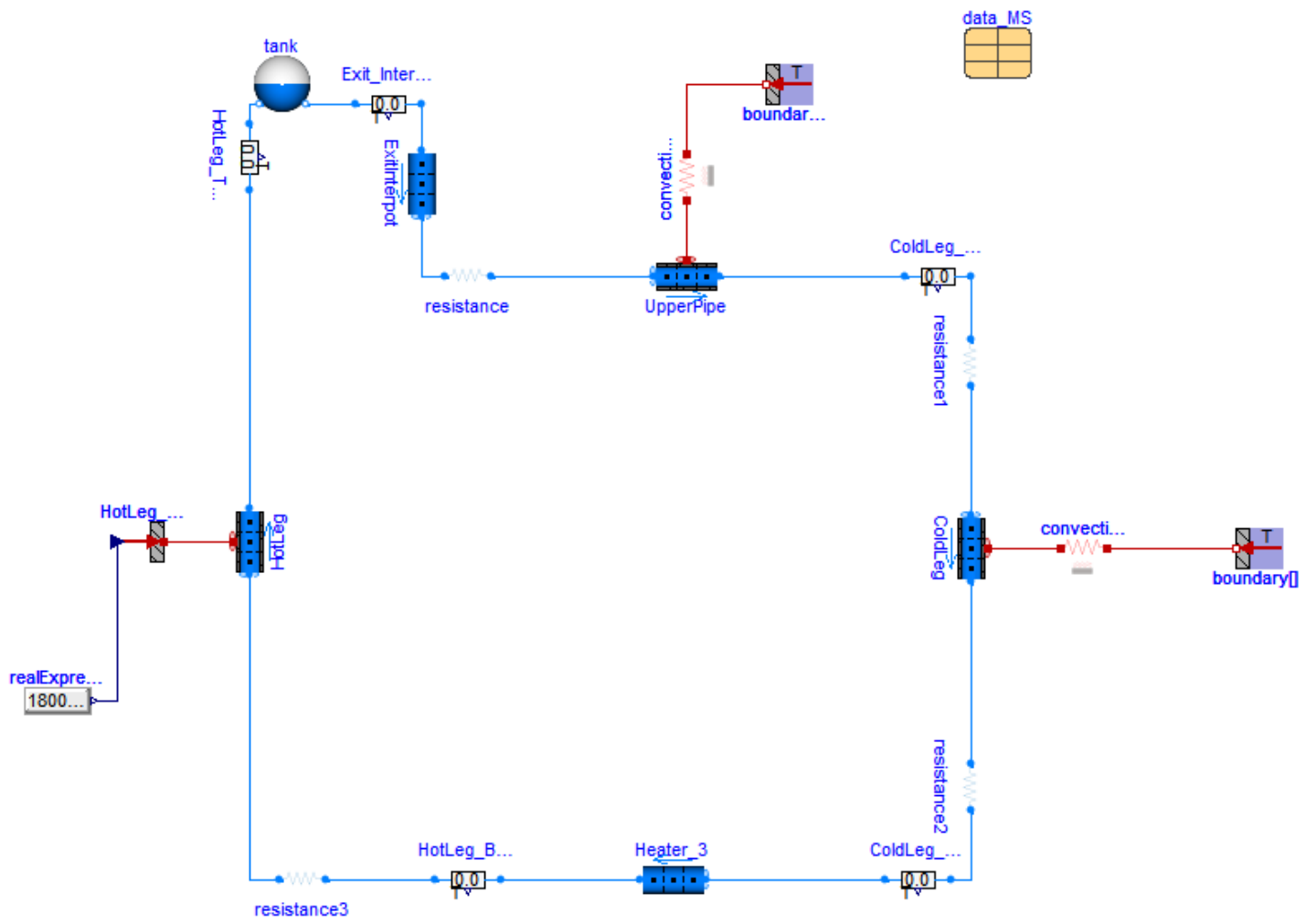

Figure 11. Schematic diagram of the TRANSFORM model of the TCL

The TRANSFORM model results were benchmarked against data taken on August 8th 2019 at 11:30 AM. At this point the TCL had reached steady state operation at $\sim 24 \mathrm{~h}$ of operation. The data points for the Bottom of the Hot Leg (BHL), Top of the Hot Leg (THL), Top of the Cold Leg (TCL), and Bottom of the Cold Leg (BCL) are shown in Figure 12a, and the results of the TRANSFORM simulation in Figure 12b. The dotted black line at $24 \mathrm{~h}$ represents the steady state benchmark that was chosen for the simulation. Data are interspersed in their time scale. The first 10 datapoints were taken at approximately 5 to 10 minute intervals to ensure temperature was maintained at the beginning of the test, and later datapoints were taken 3-12 $\mathrm{h}$ apart once the loop was maintaining steady temperatures. 

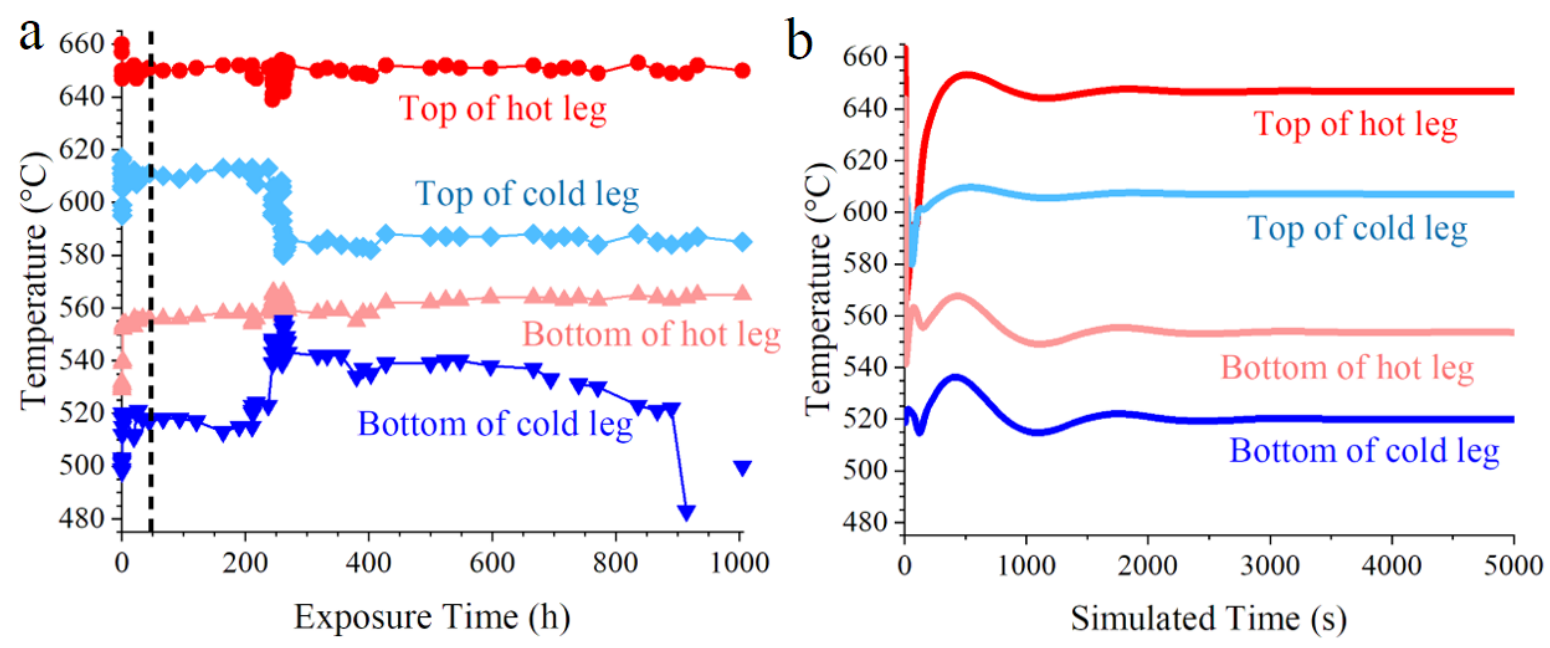

Figure 12. (a) measured temperature profile during the experiment and (b) TRANSFORM simulated temperatures at the thermocouple locations in the TCL. Simulations were based on the measured temperature at $24 \mathrm{~h}$, indicated by the dotted line on (a).

The simulated thermocouples in the TRANSFORM model match those taken by the loop thermocouples. Temperatures once the simulation reached steady state are shown in Table 3.

Table 3. Comparison of Test Steady State (SS) and Simulation Steady State Temperatures

\begin{tabular}{|l|l|l|l|l|l|}
\hline & $\begin{array}{l}\text { Exit } \\
\text { Intermed.pot }\end{array}$ & $\begin{array}{l}\text { ColdLeg } \\
\text { TCL }\end{array}$ & Coldleg BCL & Hotleg BHL & HotLeg THL \\
\hline $\begin{array}{l}\text { Test SS } \\
\text { Temperature } \\
\left({ }^{\circ} \mathrm{C}\right)\end{array}$ & 661 & 607 & 520 & 555 & 647 \\
\hline $\begin{array}{l}\text { Simulated SS } \\
\text { Temperature } \\
\left({ }^{\circ} \mathrm{C}\right)\end{array}$ & 661 & 607 & 520 & 554 & 647 \\
\hline
\end{tabular}

With these general results in hand, the detailed simulation temperature distributions for the fluid surrounding the coupons will be representative of the fluid temperatures and flows during the test. Steady state mass flow values through the loop were determined to be $9.61 \times 10^{-3} \mathrm{~kg} / \mathrm{s}$. The velocity profile around the coupons and spacers is shown for the HL and CL in Figure 13. Velocity was also measured during the experiment by locally heating an exposed section of the piping near the thermocouple at the bottom of the CL, and measuring the time for the temperature spike to reach the thermocouple at the bottom of the HL. This measurement yielded a velocity of $1.8 \mathrm{~cm} / \mathrm{s}$. Figure 14 shows the simulated temperature profiles in the HL and CL. Position is indicated by the vertical distance from the bottom of the top pot. 


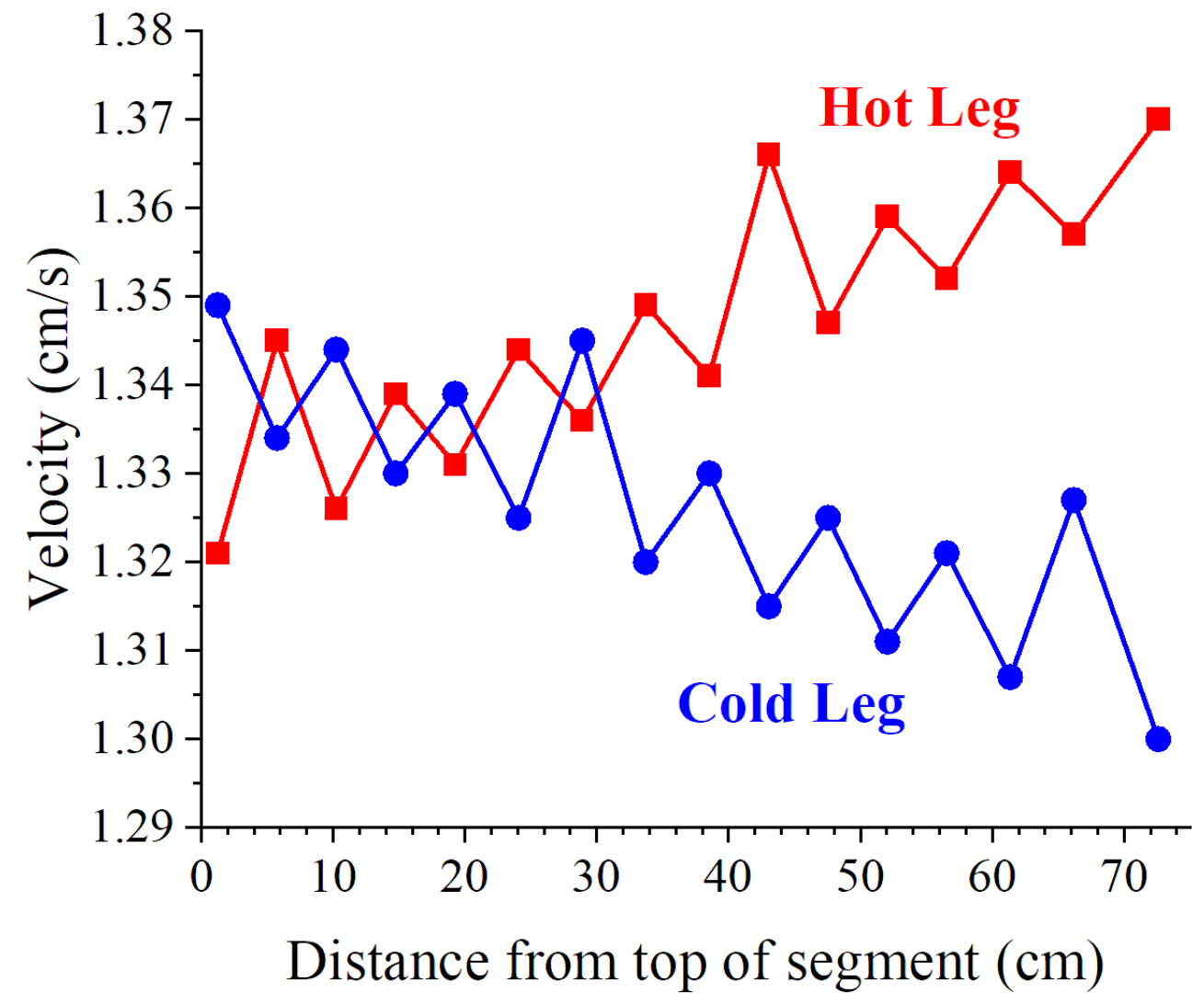

Figure 13. TRANSFORM modeled velocity profile in the hot leg and cold leg of the TCL. 


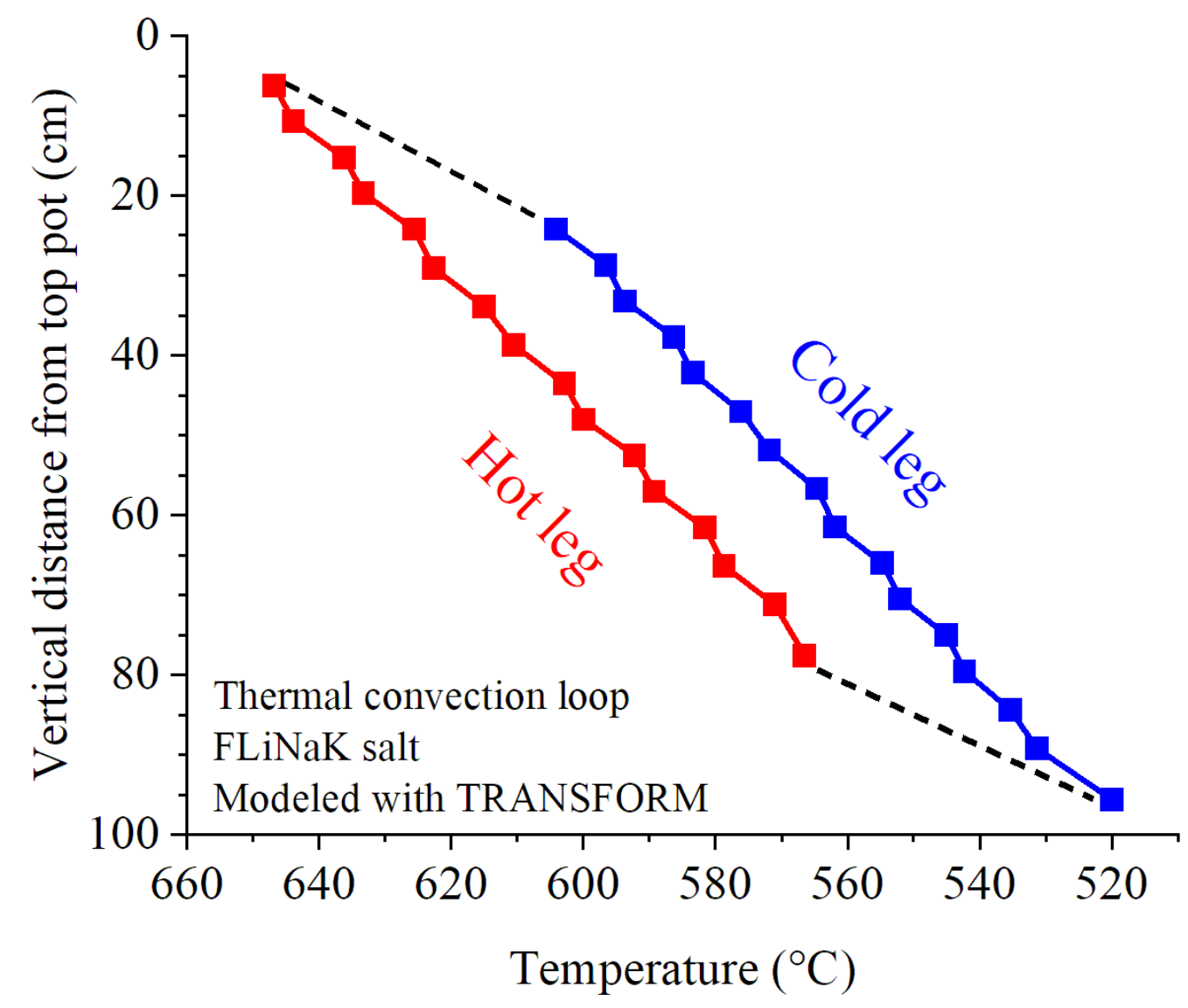

Figure 14. TRANSFORM modeled temperature profile in the hot and cold leg of the TCL.

\section{Discusson}

When analyzing the corrosion results, it is important to consider the ratio of the volume of salt to the surface area of wetted $316 \mathrm{H}$ surfaces. Figure 15 shows mass change divided by the ratio of salt volume to wetted surface area for the static and TCL experiments. This figure accounts for all wetted $316 \mathrm{H}$ surfaces including the tubing and the capsule walls.

The volume to wetted surface area ratio in the TCL is $0.9 \frac{\mathrm{cm}^{3}}{\mathrm{~cm}^{2}}$, and the ratio is $0.2 \frac{\mathrm{cm}^{3}}{\mathrm{~cm}^{2}}$ in the $316 \mathrm{H}$ capsules (the coupon area is $2.2 \mathrm{~cm}^{2}$ and the wetted capsule area is $71.4 \mathrm{~cm}^{2}$ ). The figure shows that the normalized mass loss of the HL sample was greater than the mass loss of the static experiments. This can be attributed to the mass transfer that occurred as salt flowed from the HL to the CL, and either leached or deposited corrosion product due to temperature-dependent reaction rate constants. The mass gain observed on the CL sample from the TCL confirms this mass transfer. In the static capsule experiment at $550^{\circ} \mathrm{C}$, a mass loss was observed, Figure 15. 


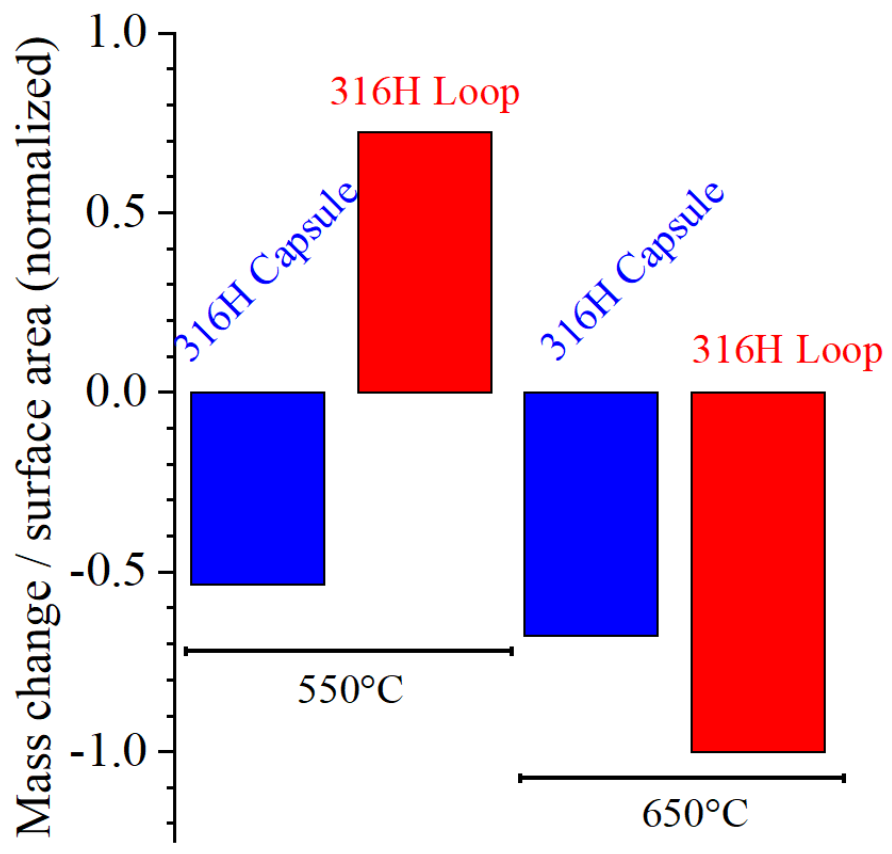

Figure 15. Normalized mass change of $316 \mathrm{H}$ samples exposed to FLiNaK salt for $1000 \mathrm{~h}$ in capsules or a TCL. Actual temperatures of the loop specimens were $552^{\circ} \mathrm{C}$ and $647^{\circ} \mathrm{C}$.

Figure 8 and 9 show that the deposited layer on the CL samples was rich in Fe compared to the other alloy components. This is surprising, since most studies discuss $\mathrm{Cr}$ transport and Figure 10 shows that $\mathrm{Cr}$ is the most abundant alloy constituent in the salt. Unfortunately, solubility data are not available for Fe and $\mathrm{Cr}$ in FLiNaK salt at these temperatures. DeVan [14] reported the amount of alloying elements (including $\mathrm{Fe}$ and $\mathrm{Cr}$ ) found in the salt after exposure of $\mathrm{Ni} 16 \%$ Mo model alloys to a U-containing FLiNaK salt. The $\mathrm{Cr}$ values were $20-80 \times 10^{-3}$ mole \% with $3-11 \% \mathrm{Cr}$ in the alloy compared to $15 \times 10^{-3}$ mole $\%$ with $4 \% \mathrm{Fe}$ present but not easily comparable to the current conditions. Several factors may be considered. First, it is possible that the $\mathrm{Cr}$ concentration in the salt never reached a high enough value in the HL, so the rate of deposition in the CL remained low. Dissolution of $\mathrm{Cr}$ into the salt would slow as the $316 \mathrm{H}$ surfaces became $\mathrm{Cr}$ depleted as shown in Figure 7. Another possibility is the kinetics of Fe deposition could be faster than the deposition kinetics of $\mathrm{Cr}$. It is also possible that the solubility of Fe in the salt changes more strongly with temperature than the solubility of Cr. If $\sim 250 \mathrm{ppm}$ $\mathrm{Cr}$ (Figure 10) is soluble in $\mathrm{FLiNaK}$ at $550^{\circ} \mathrm{C}$, then there would be no driving force for deposition in the CL. However, the $\sim 70 \mathrm{ppm}$ Fe in the salt may reflect the solubility limit in the salt at $550^{\circ} \mathrm{C}$ and if higher Fe levels were present in the HL, mass transfer of Fe would be favored [9]. Furthermore, since all of the surfaces are Fe-rich, the dissolution of Fe would continue throughout the experiment (unlike $\mathrm{Cr}$ which becomes depleted from all the specimens, Figure 7).

Figure 5 shows that all the samples in the CL, and the lower temperature samples in the HL, had a deposited layer on their surfaces. However, Figure 4 shows that only samples C10, C11, and C12 gained mass, indicating mixed mode corrosion in the other samples with a deposit. One possibility is that the samples lost their mass (e.g. Cr depletion in Figure 7) in the initial stages of exposure, while the salt corrosivity was presumably at its highest, and before the deposited layer 
formed on the sample surfaces. Another possibility is that $\mathrm{Cr}$ was still attacked after the formation of the deposited layer, but this is less likely because of the slow kinetics of $\mathrm{Cr}$ diffusion.

From a single TCL observation for one time and one temperature gradient, it is not possible to resolve these issues and further work is needed to fully understand this mechanism. It should be noted that similar Fe-rich deposits have been observed for an alloy 600 (Ni-14Cr-7Fe) TCL with $\mathrm{Cl}$ salts[41]. In both cases, interpretation is confounded by the lack of $\mathrm{Cr}$ and Fe solubility data in either salt. However, the current results do suggest that $316 \mathrm{H}$ is reasonably compatible with $\mathrm{FLiNaK}$ at $650^{\circ} \mathrm{C}$ and a reasonable candidate for further MSR-related assessments. The amount of mass transfer was minimal compared to some systems[10]. With the proper inputs, modeling efforts[42] are in progress to explain these results.

\section{Conclusions}

Demonstrating classic mass transfer behavior, type $316 \mathrm{H}$ samples in the hot leg of the FLiNaK TCL lost mass and samples in the cold leg gained mass. Samples in the intermediate range exhibited mixed mode corrosion with observed deposits, but overall mass loss. The hottest TCL sample at $650^{\circ} \mathrm{C}$ lost more mass than a $316 \mathrm{H}$ sample exposed for the same time in the same FLiNaK salt but in a static capsule, exhibiting the accelerating effect of mass transfer. Examination of the TCL cold leg samples showed that Fe was the primary deposited alloy constituent in the cold leg. The hot leg samples showed typical corrosion patterns, with $\mathrm{Cr}$ depletion near the surfaces. A TRANSFORM model of the TCL matched the measured temperature profile, showing that it is a valid tool for modeling flowing molten salt in this experiment.

\section{Acknowledgements}

The authors acknowledge the assistance of Jim Keiser, Tracie Lowe, and Victoria Cox at ORNL. This work was funded by the U.S. Department of Energy, Office of Nuclear Energy, Molten Salt Reactor Campaign.

\section{References}

[1] J. Serp, M. Allibert, O. Beneš, S. Delpech, O. Feynberg, V. Ghetta, D. Heuer, D. Holcomb, V. Ignatiev, J.L. Kloosterman, L. Luzzi, E. Merle-Lucotte, J. Uhlír, R. Yoshioka, D. Zhimin, The molten salt reactor (MSR) in generation IV: Overview and perspectives, Progress in Nuclear Energy. 77 (2014) 308-319. https://doi.org/10.1016/j.pnucene.2014.02.014.

[2] D. LeBlanc, Molten salt reactors: A new beginning for an old idea, Nuclear Engineering and Design. 240 (2010) 1644-1656. https://doi.org/10.1016/j.nucengdes.2009.12.033.

[3] W.D. Manly, G.M. Adamson, J.H. Coobs, J.H. DeVan, D.A. Douglas, E.E. Hoffman, P. Patriarca, Aircraft reactor experiment-metallurgical aspects, ORNL-2349, (1957) 59.

[4] J.H. DeVan, R.B. Evans, Corrosion behavior of reactor materials in fluoride salt mixtures, ORNL-TM-0328, (1962) 1-39. 
[5] J.W. Koger, A.P. Litman, ORNL-TM-2741 Catastrophic corrosion of type 304 stainless steel in a system circulating fused sodium fluoroborate, 1970.

[6] J.W. Koger, Evaluation of Hastelloy N Alloy After Nine Years Exposure to Both a Molten Fluoride Salt and At at Temperatures from 700 to 560C (ORNL/TM/4189), 1972.

[7] J.R. Keiser, Status of Tellurium - Hastelloy N Studies in Molten Fluoride Salts (ORNL TM-6002), 1977.

[8] J.R. Keiser, J.H. DeVan, E.J. Lawrence, Compatibility of molten salts with type 316 stainless steel and lithium, Journal of Nuclear Materials. 85-86, Par (1979) 295-298. https://doi.org/10.1016/0022-3115(79)90505-1.

[9] H. Ast, E.L. Lo, J.W. Koger, ORNL-TM-4188 Effect of FeF Addition on Mass Transfer in a Thermal Convection Loop System, 1972

[10] J.W. Koger, Evaluation of Hastelloy N Alloy After Nine Years Exposure to Both a Molten Fluoride Salt and At at Temperatures from 700 to 560C (ORNL/TM/4189), ORNL, 1972.

[11] J.L. Crowley, W.B. McDonald, D.L. Clark, Design And Operation of Forced-Circulation Corrosion Testing Loops With Molten Salt (ORNL-TM-528), 1963. https://doi.org/10.2172/4717304.

[12] V. Ignatiev, A. Surenkov, 5 - Corrosion phenomena induced by molten salts in Generation IV nuclear reactors, in: Structural Materials for Generation IV Nuclear Reactors, 2017: pp. 153-189. https://doi.org/10.1016/B978-0-08-100906-2.00005-7.

[13] D.C. Vreeland, E.E. Hoffman, W.D. Manly, Corrosion Tests for Liquid Metals, Fused Salts at High Temperatures, Nucleonics. 11 (1953) 36-39.

[14] B.-W.D. Manly, J.W. Allen, W.H. Cook, J.H. DeVan, D.A. Douglas, H. Inouye, D.H. Jansen, P. Patriarea, T.K. Roche, G.M. Slaughter, A. Taboada, G.A. Tolson, Chapter 13: Construction Materials for Molten Salt Reactors, in Fluid Fueled Reactors, 1958

[15] J.H. Devan, Effect of Alloying Additions of Corrosion Behavior of Nickel-Molybdenum Alloys in Fused Fluoride Mixtures (ORNL TM-2021), University of Tennessee, 1969.

[16] P.F. Tortorelli, J.H. Devan, J.R. Kaiser, Corrosion of Type 316 Stainless Steel in Molten LiF-LiCl-LiBr, Journal of Nuclear Materials. 103 (1981) 675-680.

[17] J.R. Distefano, J.H. Devan, J.R. Keiser, R.L. Klueh, W.P. Eatherly, Materials considerations for molten salt accelerator based plutonium conversion systems (ORNL/TM/12925/R1), (1995).

[18] J. Jun, K.A. Unocic, M.J. Lance, H.M. Meyer, B.A. Pint, Compatibility of FeCrAlMo with flowing PbLi at $500^{\circ}-650^{\circ} \mathrm{C}$, Journal of Nuclear Materials. 528 (2020) 151847. https://doi.org/10.1016/j.jnucmat.2019.151847.

[19] B.A. Pint, S.J. Pawel, M. Howell, J.L. Moser, G.W. Garner, M.L. Santella, P.F. Tortorelli, F.W. Wiffen, J.R. DiStefano, Initial characterization of $\mathrm{V}-4 \mathrm{Cr}-4 \mathrm{Ti}$ and MHD coatings exposed to flowing Li, Journal of Nuclear Materials. 386-388 (2009) 712-715. https://doi.org/10.1016/j.jnucmat.2008.12.295.

[20] S.J. Pawel, Compatibility Assessment of Advanced Stainless Steels in Sodium, Fusion Science and Technology. 61 (2012) 369-374. https://doi.org/10.13182/FST12-A13447.

[21] V. Ignatiev, A. Surenkov, Alloys compatibility in molten salt fluorides: Kurchatov Institute related experience, Journal of Nuclear Materials. 441 (2013) 592-603. https://doi.org/10.1016/j.jnucmat.2013.05.007.

[22] K. Britsch, M. Anderson, P. Brooks, K. Sridharan, Natural circulation FLiBe loop overview, International Journal of Heat and Mass Transfer. 134 (2019) 970-983. https://doi.org/10.1016/j.ijheatmasstransfer.2018.12.180. 
[23] B.A. Pint, J.W. McMurray, A.W. Willoughby, J.M. Kurley, S.R. Pearson, M.J. Lance, D.N. Leonard, H.M. Meyer, J. Jun, S.S. Raiman, R.T. Mayes, Re-establishing the paradigm for evaluating halide salt compatibility to study commercial chloride salts at $600^{\circ} \mathrm{C}-800^{\circ} \mathrm{C}$, Materials and Corrosion. 70 (2019) 1439-1449. https://doi.org/10.1002/maco.201810638.

[24] B.A. Pint, S.S. Raiman, J.R. Keiser, Lifetime modeling for a supercritical CO <inf $>2</$ inf $>$ molten salt CSP power block, in: AIP Conference Proceedings, 2019. https://doi.org/10.1063/1.5117668.

[25] H.E. McCoy, THE INOR-8 STORY., (1969).

[26] H. E. McCoy, R. L. Beatty, W. H. Cook, R. E. Gehlbach, C. R. Kennedy, J. W. Koger, A. P. Litman, C. E. Sessions \& J. R. Weir (1970) New Developments in Materials for MoltenSalt Reactors, Nuclear Applications and Technology, 8:2, 156-169, DOI: 10.13182/NT70A28622

[27] R.H. Guymon, MSRE Systems and Components Performance (ORNL-TM-3039), 1973.

[28] G. Zheng, B. Kelleher, G. Cao, M. Anderson, T. Allen, K. Sridharan, Corrosion of 316 stainless steel in high temperature molten Li2BeF4 (FLiBe) salt, Journal of Nuclear Materials. 461 (2015) 143-150. https://doi.org/10.1016/j.jnucmat.2015.03.004.

[29] R.S. Sellers, W.-J. Cheng, B.C. Kelleher, M.H. Anderson, K. Sridharan, C.-J. Wang, T.R. Allen, Corrosion of 316L Stainless Steel Alloy and Hastelloy-N Superalloy in Molten Eutectic LiF-NaF-KF Salt and Interaction With Graphite, (2017). https://doi.org/10.13182/NT13-95.

[30] G. Zheng, L. He, D. Carpenter, K. Sridharan, Corrosion-induced microstructural developments in 316 stainless steel during exposure to molten Li2BeF4(FLiBe) salt, Journal of Nuclear Materials. 482 (2016) 147-155. https://doi.org/10.1016/j.jnucmat.2016.10.023.

[31] A. V. Abramov, I.B. Polovov, V.A. Volkovich, O.I. Rebrin, Corrosion of Austenitic Stainless Steels in Chloride Melts, Molten Salts Chemistry and Technology. (2014) 427 448. https://doi.org/10.1002/9781118448847.ch6e.

[32] J.R. Keiser, Compatibility studies of potential molten-salt breeder reactor materials in molten fluoride salts (ORNL/TM/5783), (1977).

[33] ASTM A53 / A53M - 20 Standard Specification for Pipe, Steel, Black and Hot-Dipped, Zinc-Coated, Welded and Seamless. https://www.astm.org/Standards/A53.htm (accessed September 17, 2020).

[34] D. Wilson, Personal Communication, 2017.

[35] L.C. Olson, J.W. Ambrosek, K. Sridharan, M.H. Anderson, T.R. Allen, Materials corrosion in molten LiF-NaF-KF salt, Journal of Fluorine Chemistry. 130 (2009) 67-73. https://doi.org/10.1016/j.jfluchem.2008.05.008.

[36] D. Sulejmanovic, J.M. Kurley, K. Robb, S. Raiman, Validating modern methods for impurity analysis in fluoride salts, Journal of Nuclear Materials. 553 (2021) 152972. https://doi.org/10.1016/j.jnucmat.2021.152972.

[37] W.-J. Cheng, R.S. Sellers, M.H. Anderson, K. Sridharan, C.-J. Wang, T.R. Allen, Zirconium Effect on the Corrosion Behavior of 316L Stainless Steel Alloy and Hastelloy-N Superalloy in Molten Fluoride Salt, Nuclear Technology. 183 (2017) 248-259.

[38] S.S. Raiman, R.T. Mayes, J.M. Kurley, R. Parrish, E. Vogli, Amorphous and partiallyamorphous metal coatings for corrosion resistance in molten chloride salt, Solar Energy Materials and Solar Cells. 201 (2019) 110028. https://doi.org/10.1016/j.solmat.2019.110028. 
[39] M.S. Greenwood, TRANSFORM - TRANsient Simulation Framework of Reconfigurable Models. Computer software, Oak Ridge National Laboratory., (2017). https://doi.org/10.11578/dc.20171025.2022.

[40] M.S. Greenwood, B.R. Betzler, A. Lou Qualls, J. Yoo, C. Rabiti, Demonstration of the Advanced Dynamic System Modeling Tool TRANSFORM in a Molten Salt Reactor Application via a Model of the Molten Salt Demonstration Reactor, Nuclear Technology. 206 (2020) 478-504. https://doi.org/10.1080/00295450.2019.1627124.

[41] B.A. Pint, J.M. Kurley, D. Sulejmanovic, Performance of alloy 600 in flowing commercial $\mathrm{Cl}$ salt at $600^{\circ}-750^{\circ} \mathrm{C}$, in: in press.

[42] R. Pillai, S.S. Raiman, B.A. Pint, First steps toward predicting corrosion behavior of structural materials in molten salts, Journal of Nuclear Materials. 546 (2021) 152755. https://doi.org/10.1016/j.jnucmat.2020.152755. 